\title{
Correction to: Time resolution effect on the apparent particle dynamics confined in a nanochannel evaluated by the single particle tracking subject to Brownian motion
}

\author{
Itsuo Hanasaki ${ }^{1}\left[\right.$ (]) Yutaka Kazoe ${ }^{2} \cdot$ Takehiko Kitamori $^{2}$
}

Published online: 23 September 2020

(c) Springer-Verlag GmbH Germany, part of Springer Nature 2020

\section{Correction to: Microfluidics and Nanofluidics (2018) 22:56 https://doi.org/10.1007/s10404-018-2073-1}

There was a typo in Eq. (4) in the original manuscript of "Time resolution effect on the apparent particle dynamics confined in a nanochannel evaluated by the single particle tracking subject to Brownian motion", Microfluidics and Nanofluidics, Vol. 22, 56 (2018). The correct equation for Eq. (4) is described as follows:

$\alpha^{-1}(z)=\alpha_{\text {top }}^{-1}(z)+\alpha_{\text {bottom }}^{-1}(z)-1$.

The simulations are based on this correct equation.

The original article can be found online at https://doi.org/10.1007/ s10404-018-2073-1.

Itsuo Hanasaki

hanasaki@cc.tuat.ac.jp

1 Institute of Engineering, Tokyo University of Agriculture and Technology, 2-24-16 Naka-cho, Koganei-shi,

Tokyo 184-8588, Japan

2 Department of Applied Chemistry, School of Engineering, The University of Tokyo, 7-3-1 Hongo, Bunkyo,

Tokyo 113-8656, Japan
Publisher's Note Springer Nature remains neutral with regard to jurisdictional claims in published maps and institutional affiliations. 